\title{
Numerical Investigation of the Transient Multiphase Flow in an Ironmaking Blast Furnace
}

\author{
Zongyan ZHOU, ${ }^{1)}$ Haiping ZHU, ${ }^{1)}$ Aibing $\mathrm{YU}^{11}$ and Paul ZULLI ${ }^{2 !}$ \\ 1) Laboratory for Simulation and Modelling of Particulate Systems, School of Materials Science and Engineering, The \\ University of New South Wales, Sydney, NSW 2052 Australia. E-mail: a.yu@unsw.edu.au \\ 2) BlueScope Steel Research, P.O. Box 202, Port Kembla, NSW 2505 Australia.
}

(Received on October 13, 2009; accepted on January 21, 2010)

\begin{abstract}
Discrete particle simulation (DPS) has been applied to multiphase flow modelling in an ironmaking blast furnace (BF), including burden distribution at the top, gas-solid flow in the BF shaft and raceway, and liquid-solid flow in the hearth. In this work, the approach is further extended to take into account the transient features of gas and particle flow coupled with liquid tapping operation. In the simulation, two types of particles of coke and ore with different physical properties are considered, together with different shapes of the cohesive zone and the shrinkage of size of ore particles in the cohesive zone to present ore reduction. The simulated results show that the flow of both solid and gas phases varies spatially and temporally, particularly in the cohesive zone. Gas flow is strongly affected by the layered structure of ore and coke particles in the cohesive zone. A coke-free zone can form in the hearth, and the boundary profile between the coke-free zone and the coke bed depends on the amount of liquid accumulated in the hearth, gas and solid flow rates in the raceway, and coke consumption in different regions at the interface of liquid and the coke bed. The results show that the complicated transient multiphase-flow in a BF can be captured by the present approach which may be extended to account for heat transfer and chemical reaction in the future.
\end{abstract}

KEY WORDS: multiphase flow; discrete particle simulation; computational fluid dynamics; blast furnace; cohesive zone.

\section{Introduction}

Blast furnace $(\mathrm{BF})$ is a large chemical reactor that is predominantly used for ironmaking. In this process, solid particles, primarily consisting of coke (as a reductant) and ore (as iron-bearing materials), are charged into a BF at the top layer by layer alternatively, and then descend under gravity. Due to the softening and melting of ore particles, ore layers become impermeable to gas flow, giving the so-called cohesive zone. Ore particles are reduced and melt to liquid iron in this zone, while coke particles descend further to the raceway and the hearth. Gases, injected into the raceway with pulverized coal powder, pass through the coke-packed bed, and escape from the top. Liquid iron and slag, produced from ore reduction in the cohesive zone, descend through the voids among coke particles to the hearth. The behaviour of solid particles in the hearth is strongly affected by the liquid level, gas and solid flow rates. Thus, for such a multiphase flow system, the smooth and stable operation of gas-solid-liquid flow is very important to achieve high efficiency.

Numerous studies related to the multiphase flow in a BF have been carried out in the past decades either experimentally $^{1-6)}$ or mathematically. ${ }^{7,8)}$ Particularly numerical simulations based on different approaches increasingly become an important research tool to obtain some insight into the phenomena occurring in a BF. Generally, two approaches are widely used: the continuum approach at a macroscopic level and the discrete approach at a microscopic level. The continuum approach, based on local average principles, is preferred in process modelling and applied research. However, its effective use heavily depends on constitutive or closure relations. In the past, various theories and empirical treatments have to be employed to describe the granular flow for different materials and for different flow regimes. When applied to study solid flow in a BF, such a continuum model often requires certain assumptions or arbitrary treatments in order to, for example, describe the deadman and associated flow features. ${ }^{9-14)}$ Discrete particle simulation (DPS), mainly based on the so-called Discrete Element Method (DEM) originally developed by Cundall and Strack, ${ }^{15)}$ has been applied in many fields including process engineering, mining, and geophysics, and recognized as an effective method to study the fundamentals of granular materials. ${ }^{16,17)}$ Although still experiencing difficulties in adapting it to process modelling because of the limited number of particles which can be handled with the present computational capacity, the approach has been found to be useful in the study of the micromechanics of granular materials in a way that is difficult to achieve by other approaches.

The application of DPS to BF has been made by some researchers on various aspects, including burden distribution at the top, ${ }^{18-21)}$ gas-solid flow in $\mathrm{BF}$ shaft ${ }^{2-26)}$ and raceway, ${ }^{27-33)}$ and solid behaviour in the hearth. ${ }^{34,35)}$ Most of 
those studies are mainly focused on a particular region, e.g. raceway or hearth, in a $\mathrm{BF}$ under simplified conditions. Some studies ${ }^{27-33)}$ use a combined approach of DPS and CFD (Computational Fluid Dynamics) to investigate the influence of gas phase on solid flow in a BF, mainly focused on the raceway where gas-solid interaction is strong. The success, although largely limited to academic investigation, prompts larger scale, more detailed analysis of solid flow in a BF by the discrete approach.

In connection with our previous studies, ${ }^{23,24,36)}$ a simulation study of the transient multiphase flow is performed in this work under complicated conditions. The transient features of gas and particle flow together with the present hearth liquid are considered in the simulation. Two types of particles are considered, representing coke and ore, respectively. The structures of this coupled gas and solid flow are examined first. Then the simulation is then extended to consider the liquid present in the furnace hearth. The effects of liquid level, gas flow rate, and solid flow rate on solid flow at the BF bottom are investigated mainly in terms of solid flow patterns. Note that the aim of this study is to understand the complicated flow phenomena in a BF. Thermochemical behavior is not considered for simplicity.

\section{Model Descriptions}

A particle can have two types of motion: translational and rotational, determined by Newton's second law of motion. During its movement, the particle may collide with its neighbor particles or wall at the contact points and interact with the surrounding fluid, through which the momentum and energy are exchanged. At any time $t$, the governing equations for the translational and rotational motion of particle $i$ with radius $R_{i}$, mass $m_{i}$ and moment of inertia $I_{i}$ can be written as

$$
\begin{aligned}
& m_{i} \frac{d \mathbf{v}_{i}}{d t}=\mathbf{f}_{p f, i}+\sum_{j=1}^{k_{c}}\left(\mathbf{f}_{c, i j}+\mathbf{f}_{d, i j}\right)+m_{i} \mathbf{g} \\
& I_{i} \frac{d \boldsymbol{\omega}}{d t}=\sum_{j=1}^{k_{c}}\left(\mathbf{M}_{t, i j}+\mathbf{M}_{r, i j}\right)
\end{aligned}
$$

where $\mathbf{v}_{i}$ and $\boldsymbol{\omega}_{i}$ are respectively the translational and angular velocities of the particle, and $k_{c}$ is the number of particles in interaction with the particle. The forces involved are: particle-fluid interaction force $\mathbf{f}_{p f, i}$, the gravitational force $m_{i} \mathbf{g}$, and inter-particle forces between particles which include elastic force $\mathbf{f}_{c, i j}$ and viscous damping force $\mathbf{f}_{d, i j}$. The torque acting on particle $i$ by particle $j$ includes two components: $\mathbf{M}_{t, i j}$ generated by the tangential force, and $\mathbf{M}_{r, i j}$ commonly known as the rolling friction torque.

The continuum fluid field is calculated from the continuity and the Navier-Stokes equations based on the local mean variables over a computational cell, which are given by

$$
\begin{array}{r}
\frac{\partial \varepsilon_{f}}{\partial t}+\nabla \cdot\left(\varepsilon_{f} \mathbf{u}\right)=0 \ldots \ldots \ldots \ldots \ldots \ldots \ldots \ldots \ldots \ldots \ldots \ldots \ldots \ldots \ldots \\
\frac{\partial\left(\rho_{f} \varepsilon_{f} \mathbf{u}\right)}{\partial t}+\nabla \cdot\left(\rho_{f} \varepsilon_{f} \mathbf{u u}\right)=-\nabla p-\mathbf{F}_{p f}+\nabla \cdot\left(\varepsilon_{f} \boldsymbol{\tau}\right)+\rho_{f} \varepsilon_{f} \mathbf{g}
\end{array}
$$

where $\mathbf{u}$ and $p$ are respectively the fluid velocity and pressure; $\boldsymbol{\tau}, \varepsilon_{f}$ and $\mathbf{F}_{p f}\left(=\sum_{i=1}^{k_{c}} \mathbf{f}_{p f, i}\right) / \Delta V$ are the fluid viscous stress tensor, porosity, and particle-fluid interaction force in a computational cell of volume $\Delta V$. Equations to calculate the interaction forces between particles and between particle and fluid can be found in Table 1, which has been used in our previous work. . $3,24,27-29,37-39)^{2}$

Table 1. Components of forces and torque acting on particle $i$.

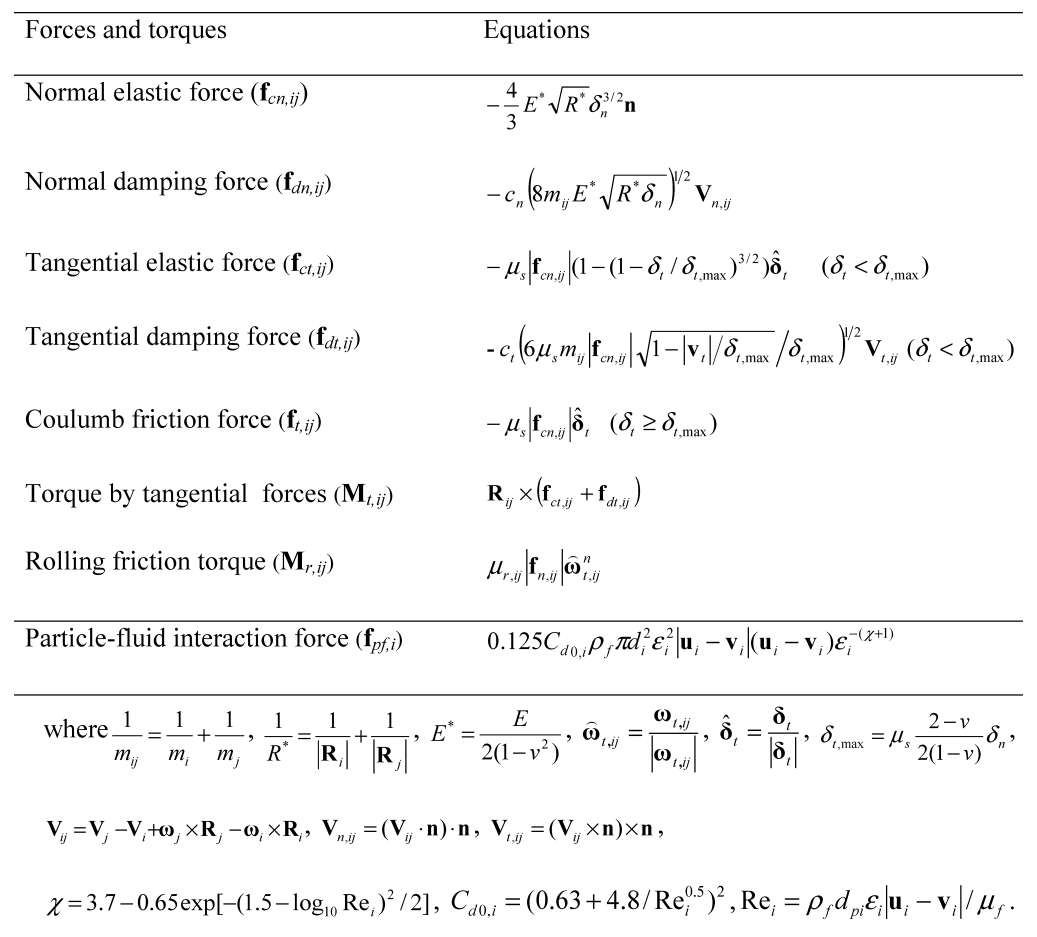

Note that tangential forces $\left(\mathbf{f}_{c t, i j}+\mathbf{f}_{d t, i j}\right)$ should be replaced by $\mathbf{f}_{t, i j}$ when $\delta_{t} \geq \delta_{t, \max }$. 
The modelling of the solid flow by DPS is at the individual particle level, whilst the fluid flow by CFD is at the computational cell level. Their coupling is numerically achieved as follows. At each time step, DPS will give information, such as the positions and velocities of individual particles, for the evaluation of porosity and fluid drag force in a computational cell. CFD will then use these data to determine the gas flow field which then yields the fluid drag forces acting on individual particles. Incorporation of the resulting forces into DPS will produce information about the motion of individual particles for the next time step. This coupling scheme has been well documented in the literature and used in our previous studies. ${ }^{16,28,38)}$

\section{Simulation Conditions}

The gas-solid features considered and assumptions made in the present simulations are described below:

a) To reduce the computational effort limited by the number of particles, a slot model is considered with the thickness of 4 particle diameters. Periodic boundary conditions are applied at the front and rear planes to reduce the wall effect.

b) Two types of spherical particles are considered, coke and ore, with each having its own physical properties.

c) The surface of burden distribution at the top is flat, and coke and ore layers are alternatively charged uniformly onto the surface.

d) Cohesive zones of different shapes ( $\mathrm{V}$, inversed V, and $\mathrm{W})$ are considered and pre-set for a simulation. The reduction of ore particles in this region is considered by their shrinking to small particles. The transient diameter of ore particles in the cohesive zone is determined by $d_{\text {ore }}=d_{0, \text { ore }}-\left(d_{0, \text { ore }}-d_{c \text { ore }}\right)\left(Z_{\text {top }}-Z_{p}\right) /\left(Z_{\text {top }}-Z_{\text {bot }}\right)$, where $d_{c, \text { ore }}$ is the critical diameter of ore particles when leaving the cohesive zone (set to $0.2 d_{0, \text { ore }}$ and $d_{0 \text {,ore }}$ is the original diameter of ore particles), and $Z_{\text {top }}, Z_{\text {bot }}$ and $Z_{p}$ are vertical distances to the bottom wall as shown in Fig. 1. When ore particles leave the cohesive zone, they become liquid, which is however not considered in this work focused on solid behavior. The ore layers in this softening and melting zone are impermeable to gas flow; and gas only passes through the coke layer in this region. The layered structure such as the size, shape and location of ore and coke layers in this region can be identified automatically in the simulation.

e) Particles are discharged at a certain rate from raceway continuously representing coke combustion with oxygen, and the discharging rate is based on the modified Froude number at the BF throat. ${ }^{5,23,24)}$

f) Liquid iron is assumed to be present in the hearth in a hydrostatic state; and the height of liquid level can increase or decrease at a certain rate $\left(80 \mathrm{~mm} \cdot \mathrm{s}^{-1}\right.$ is used in the present simulation) to represent the accumulating or tapping process.

g) The region occupied by liquid iron in the hearth is impermeable to gas phase. The effect of gas flow on liquid phase is small, ${ }^{40)}$ and ignored in the present simulation.

h) Different colors are used to identify different particles and different regions, as given in the figures.

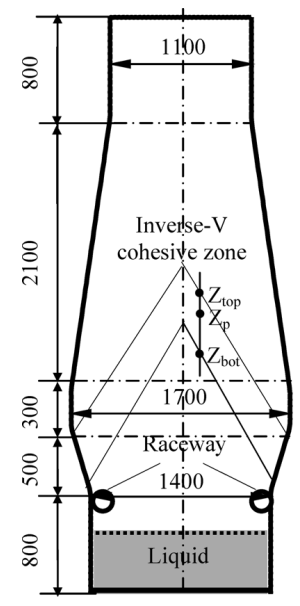

(a)

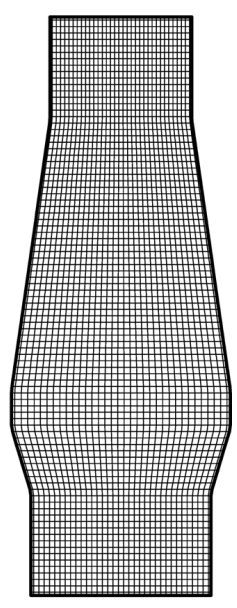

(b)
Fig. 1. (a) Geometry of the BF model used in the simulation (mm), and (b) body-fitted CFD cells for gas phase.

The procedure for the numerical experiment is described as follows. 25000 spherical and uniform particles are firstly generated in the model BF, as shown in Fig. 1, without considering gas blast, hearth liquid, and particle discharging from the raceway. After the structure of the packed bed is established, particles are then removed from the raceway at a rate to represent the coke combustion. The discharged particles are added to the top, and distinguished by the alternative layers using different colors, coke layer (500 coke particles) and ore layer (1000 ore particles). At the same time, gas phase is switched on and injected into the furnace through the raceway. The position of the inverse-V shaped cohesive zone and its boundary are preset (see Fig. 1(a)). When the ore layers descend to this region, ore particles in the cohesive zone begin to shrink to smaller size according to their positions. When ore particles descend further, and leave the cohesive zone, it is assumed that they are completely consumed, and removed from the simulation. After reaching the steady state under the above conditions, liquid is introduced into the hearth by increasing its level slowly. Then, the particles which are immersed or partially immersed in the liquid (identified by another color) will be acted by the buoyancy force and drag force. When the liquid level reaches $0.7 \mathrm{~m}$, the introduction of the liquid is stopped. Then the steady state under this condition is set as base condition in the simulation.

As shown in Fig. 1(a), the total height of the model is set to $4.5 \mathrm{~m}$ with a hearth diameter of $1.4 \mathrm{~m}$, which is like an experimental BF. Other parameters, i.e. particle properties, used in the simulation are listed in Table 2. Gas density, $\rho_{f}$, and viscosity, $\mu_{f}$, are $1.205 \mathrm{~kg} \cdot \mathrm{m}^{-3}$ and $1.8 \times 10^{-5}$ $\mathrm{kg} \cdot \mathrm{m}^{-1} \cdot \mathrm{s}^{-1}$, respectively. The blast jet opening (tuyere size) is $50 \mathrm{~mm}$ high, and 4 particle diameter wide. The computational grid for the CFD solution consists of $36 \times 92$ body-fitted cells, as shown in Fig. 1(b). Liquid density $\rho_{l}$ is set to $7000 \mathrm{~kg} \cdot \mathrm{m}^{-3}$, and viscosity $\mu_{l} 1.0 \times 10^{-2} \mathrm{~kg} \cdot \mathrm{m}^{-1}$. $\mathrm{s}^{-1}$. The coke discharging rate from the raceway is 2 particles every 100 time steps, which corresponds to 7.34 $\mathrm{kg} \cdot \mathrm{s}^{-1}$. The inject gas velocity at the tuyere is set to $30 \mathrm{~m} \cdot \mathrm{s}^{-1}$ for the base condition, giving the gas flow rate of $0.29 \mathrm{~kg} \cdot \mathrm{s}^{-1}$. The corresponding modified Reynolds number 
Table 2. Particle properties and simulation conditions.

\begin{tabular}{ll}
\hline \multicolumn{1}{c}{ Variables } & Base values \\
\hline Number of particles $(\mathrm{N})$ & 25,000 \\
Diameter of coke particles & $40 \mathrm{~mm}$ \\
Diameter of ore particles & $30 \mathrm{~mm}$ \\
Density of coke particles & $700 \mathrm{~kg} \cdot \mathrm{m}^{-3}$ \\
Density of ore particles & $3000 \mathrm{~kg} \cdot \mathrm{m}^{-3}$ \\
Particle-particle sliding friction coefficient $\left(\mu_{\mathrm{s}, \mathrm{pp}}\right)$ & 0.4 \\
Particle-wall sliding friction coefficient $\left(\mu_{\mathrm{s}, \mathrm{pw}}\right)$ & 0.4 \\
Particle-particle rolling friction coefficient $\left(\mu_{\mathrm{r}, \mathrm{pp}}\right)$ & $0.4 \mathrm{~mm}$ \\
Particle-wall rolling friction coefficient $\left(\mu_{\mathrm{r}, \mathrm{pw}}\right)$ & $0.4 \mathrm{~mm}$ \\
Young's modulus (E) & $6.0 \times 10^{6} \mathrm{~Pa}$ \\
Poisson ratio $(v)$ & 0.3 \\
Time step $(\Delta \mathrm{t})$ & $6.388 \times 10^{-5} \mathrm{~s}$ \\
Gas inject velocity & $30 \mathrm{~m} \cdot \mathrm{s}^{-1}$ \\
Solid flow rate & $7.34 \mathrm{~kg} \cdot \mathrm{s}^{-1}$ \\
\hline
\end{tabular}

for gas flow, defined as $\operatorname{Re}=\rho_{f} d_{p} U_{f} / \mu_{f}$ where $U_{f}$ is the gas superficial velocity at the furnace throat and $d_{p}$ is the diameter of coke particles, ${ }^{24)}$ is $3.64 \times 10^{3}$. This is equivalent to the Reynolds number of $10^{3}-10^{4}$ at the throat in a real blast furnace.

In our previous study, ${ }^{23)}$ the DPS method has been validated in terms of solid flow patterns in a small scale 2D slot model under the condition without gas flow. It confirms that the main solid flow features in a BF is captured successfully in such a model, and thus enables us to go further to investigate the gas-solid flow behaviour by coupling with CFD. Such an approach is particularly used in raceways, validated by comparing simulated and measured flows under comparable condtions. ${ }^{28)}$ The solid flow in the hearth has been examined by Nouchi et al. ${ }^{34,35)}$ The gas-solid flow behavior is further examined focusing on the gas effect and stress state in a $\mathrm{BF}^{24,36)}$ It can be evident from those studies that the DPS or DPS-CFD approach is useful and validated, at least for flows in a BF. Thus, in this work, in connection with our previous studies, we continue to use such a combined approach to examine more complicated BF phenomena, particularly the effects of several variables such as different particles, cohesive zone, gas flow and liquid presence. The discussions are based on general flow structures, the gas and solid flow in the cohesive zone regions, the stress field and in particular, the solid behaviour in the hearth.

\section{Results and Discussion}

\subsection{General Flow Structure}

The general solid flow pattern obtained from the present simulation is shown in Fig. 2(a). It demonstrates that two different layers (coke layer with 500 coke particles, and ore layer with 1000 ore particles, identified by different colors) descend uniformly from the top part. Obviously, with the divergent geometry, the thickness of layers decreases. Parti-

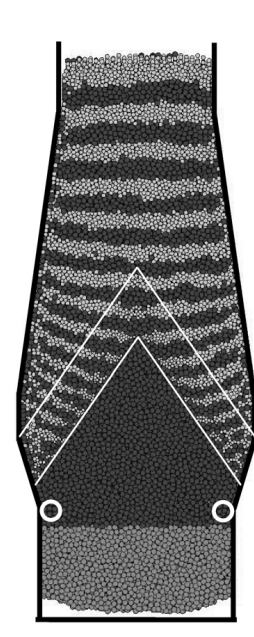

(a)

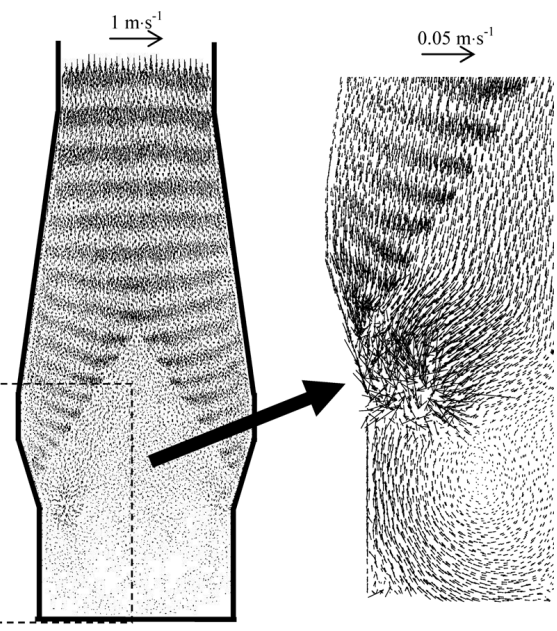

(b) (c)
Fig. 2. (a) Snapshot of solid flow patterns (blue color: coke; green: ore; red: coke in the liquid), (b) particle velocity vectors, and (c) particle velocity vectors around the raceway region.

cles are mixed in the vicinity of the side wall due to the wall resistance to the solid flow, forming a mixing zone along the side wall. In the cohesive zone, ore particles shrink to smaller particles at a certain rate due to reduction, and vanish below the cohesive zone. Coke particles descend further to the raceway region and the hearth. With the existence of liquid, the bottom part of the whole particle bed is immersed in the liquid (identified by the red color). A cokefree zone could be formed if the liquid level is high. More details of the effect of liquid level, gas and solid flow rate on the hearth solid flow behaviour will be discussed later.

The use of DPS makes it possible to capture the flow details of each particle. Figure 2(b) shows a snapshot of the spatial distribution of individual particle velocity vectors, which corresponds to the solid flow pattern in Fig. 2(a). It is observed that, above the cohesive zone, particles have high descending velocities due to the ore consumption, i.e. the shrinkage of size of ore particles, in the cohesive zone. Particles in the raceway also have high velocities, as shown in Fig. 2(c). This is because coke particles are consumed there and the left voids are replaced quickly by those in the vicinity of the raceway. Also, it is interesting to observe that the replacing particles could also come from the bottom. As shown in Fig. 2(c), the velocity vectors of particles in the hearth liquid have a tendency of flowing towards the raceway, which is caused by the strong buoyancy force.

Figure 3(a) shows the descending process of a single coke layer from the top to the bottom. It can be observed that the shape of the coke layer is slightly distorted from flat to $\mathrm{V}$ and $\mathrm{W}$ shapes during its descent in the shaft. This is caused by different descending velocities of the layer across the section. All the coke particles have the tendency of flowing toward the raceway, i.e. the main coke consumption region. Particles in the hearth are acted upon by the large liquid buoyancy force (density of liquid, 7000 $\mathrm{kg} \cdot \mathrm{m}^{-3}$ ). Thus, the particles in the hearth also flow towards the raceway, as indicated by the velocity vectors in Fig. 3(b). So the coke particles in the central bottom are re- 
newed with time, and replaced by particles from the central top. Those features are consistent with those observed in the literature. $22,41,42$ )

\subsection{Gas and Solid Flow in the Cohesive Zone}

In a real $\mathrm{BF}$, the cohesive zone is formed due to the softening and melting of ore particles. Thus, the ore layers may become impermeable to gas, and will strongly affect the gas flow direction, i.e. the gas distribution is rearranged in this zone. In this work, a typical shape of cohesive zone considered is inverse- $\mathrm{V}$, and its up and bottom boundaries are assumed fixed. In the previous physical or mathematical studies, the layers of ore in the cohesive zone are often preset, consisting of a series of fixed blocks. ${ }^{8)}$ The assumption of fixed blocks is not necessary here, and the model can identify the position of an ore layer and its movement in the cohesive zone. Figure 4 shows the solid flow patterns and gas flow field around the cohesive zone region. It can be seen

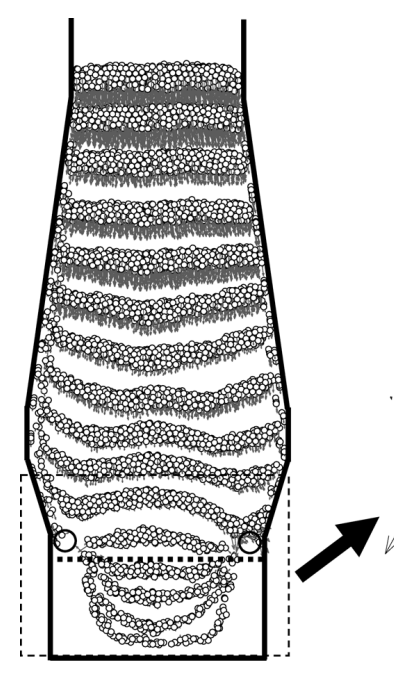

(a)

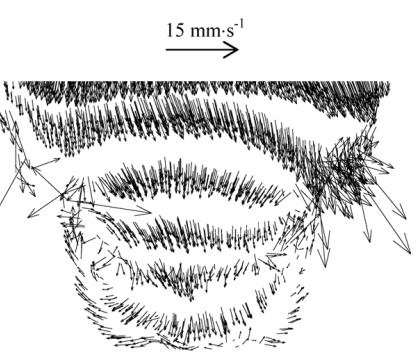

(b)
Fig. 3. (a) Coke layer descending process (the bold dash line represents the liquid level), and (b) and particle velocity vectors of coke layer at the lower part. that the positions of ore layers in the cohesive zone vary with time, and the flow is transient. Correspondingly, gas flow is also transient. The gas flow field in the cohesive zone is determined by the positions of ore and coke layers. Thus, the distribution of such a gas flow field also in turn affects the solid flow behaviour.

Note that the gas flow would be different for other cohesive zone shapes, i.e. $\mathrm{V}$ - or $\mathrm{W}$-shaped. The present model can also be used to study the gas and solid flow phenomena inside BF with such settings, as shown in Fig. 5. For the Vshaped cohesive zone, the gas flow direction is from periphery to center, completely different from the inverse- $\mathrm{V}$ shaped cohesive zone. For the W-shaped cohesive zone, gas flow field is similar to the inversed V, except for a slight difference of gas flow in the vicinity of the side wall region. It demonstrates that cohesive ore layers, acting as a gas distributor, determine the gas flow trends, which is consistent with those observed in physical experiment and simulated by two-fluid model. ${ }^{43}$ ) Different cohesive zones will also give different powder holdup behavior as, for example, demonstrated by Dong et al. ${ }^{43)}$ In this work focused on flow phenomena only, the profile of a cohesive zone is pre-set. There is a need to extend the present approach to consider the heat and mass transfer, so that this assumption can be eliminated. This will be done in the future.

\subsection{Stress State in BF}

Proper quantification of gas-solid and solid-solid interactions is key to developing a better understanding of the mechanisms governing the complicated gas-solid flow. Therefore, the analysis of the microdynamic behaviour requires information about the transient forces acting on individual particles. The stress distribution in a model $\mathrm{BF}$ based on DPS has been examined, ${ }^{24,25,36}$ ) showing some promising results. In this work, the forces such as particle-particle (including particle-wall) contact force and particle-fluid force are examined under the present model conditions.

The contacts among particles in a particle system actually represent the particle connectivity and hence the force network. The present simulation considers the contact forces between particles such as the normal and tangential

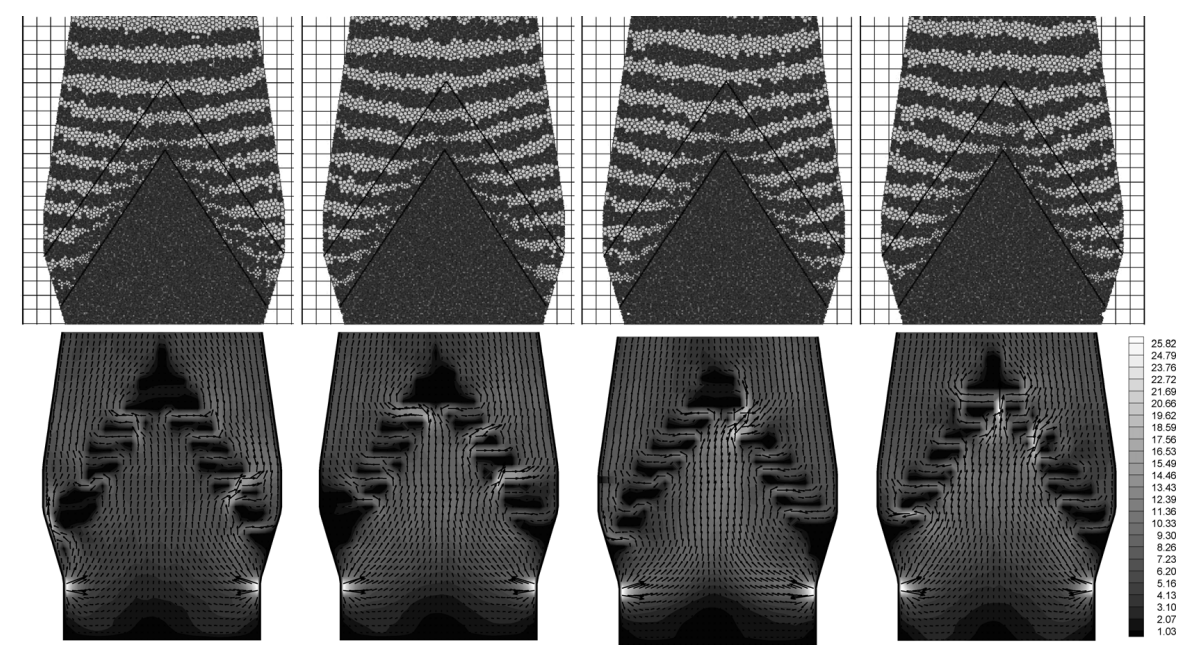

Fig. 4. Snapshots of solid flow patterns (top), and corresponding gas flow fields (units: $\mathrm{m} \cdot \mathrm{s}^{-1}$ ) (bottom) in the cohesive zone and surrounding region with time interval $0.42 \mathrm{~s}$. 

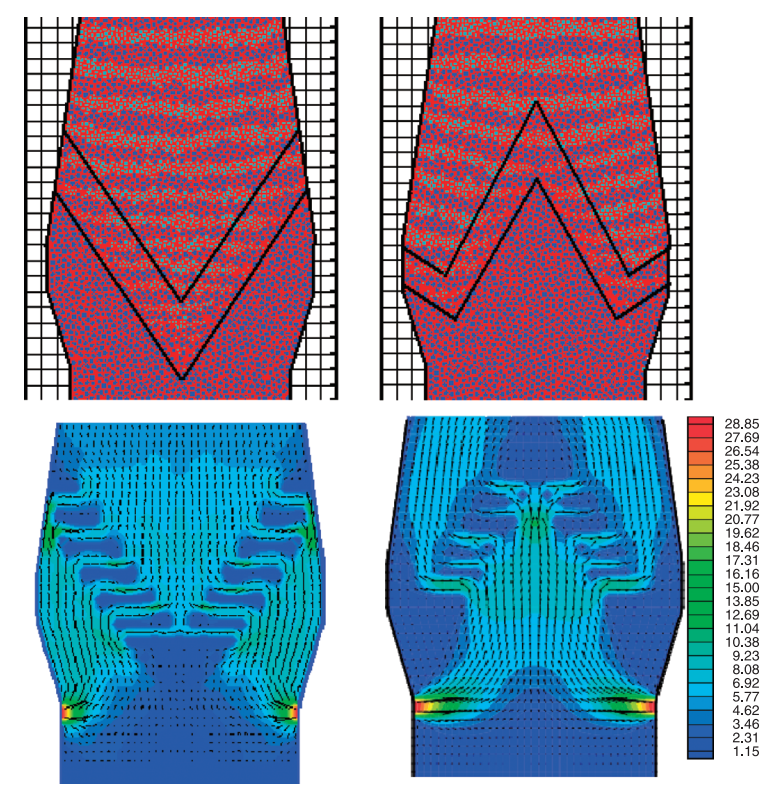

Fig. 5. Snapshots of solid flow patterns (top) and corresponding gas velocity fields (units: $\mathrm{m} \cdot \mathrm{s}^{-1}$ ) (bottom) for V-shaped cohesive zone (left figure) and W-shaped cohesive zone (right figure) in the cohesive zone and surrounding region.

forces due to the plastic and elastic deformation resulting from particle collision, sliding and rolling frictions, in addition to the gravity force. It has been illustrated that among these forces, the normal contact force is the most important as other contact forces are all related to it (please refer to Table 1). Figure 6(a) shows the distribution of the normal contact forces in which the size of a connection represents the magnitude of the force between two particles. It can be observed that the particles in the lower central bottom experience large normal forces. This is because these particles need to support the particles above them. On the contrary, particles exhibit weak force network around the raceway and in the fast flow zone. This is because particles in these regions flow fast and there exist more voids and disconnections among particles. There are also strong interactions between particles and side walls, as seen in Fig. 6(b). The large normal contact force between particle and wall results in large friction forces which resist the descent of particle layers. Thus, a mixing zone forms, as indicated in Fig. 2(a).

Figure 7 shows the spatial distribution of the particlefluid interaction force in the vertical and horizontal directions, respectively. A negative value means its corresponding force acting in the opposite direction. As seen in Fig. 7(a), large vertical drag forces just below the cohesive are observed, mainly as a result of the large vertical gas velocity there. In the cohesive zone, the vertical forces are very small. This is because in this region, gas phase is forced to change flow direction from vertical to horizontal. Thus, large horizontal drag forces are observed, as shown in Fig. 7(b). At the tuyere level, high gas blast velocity in the horizontal direction leads to the largest horizontal drag forces. At the bottom part occupied by liquid, no drag forces from gas exist, but buoyancy force and drag force from hearth liquid. Obviously, the phenomena are in general agreement with our common sense. However, microscopic information obtained from DPS-CFD can help develop better under-

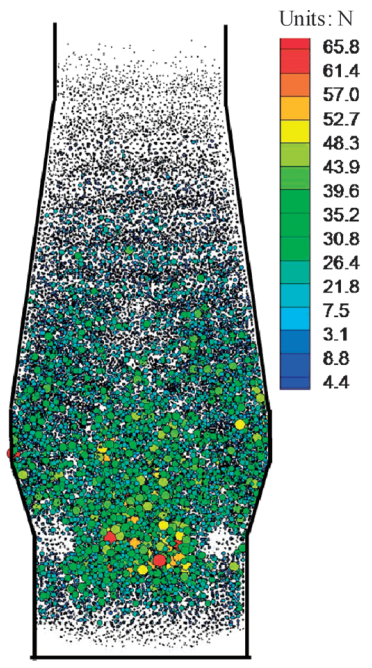

(a)

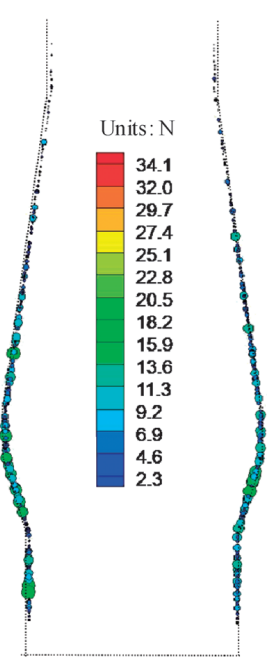

(b)
Fig. 6. Spatial distributions of the normal contact forces between (a), particle and particle; and (b), particle and walls.

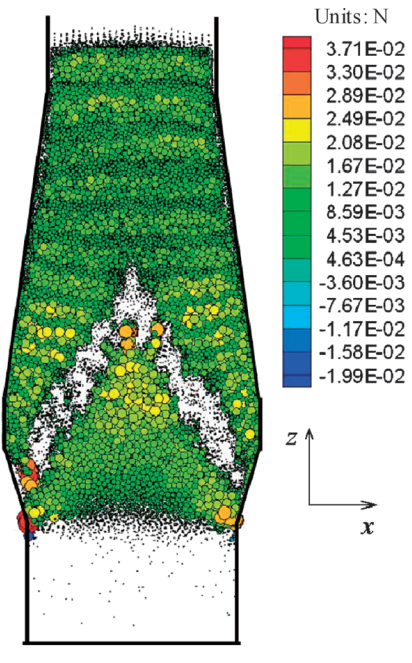

(a)

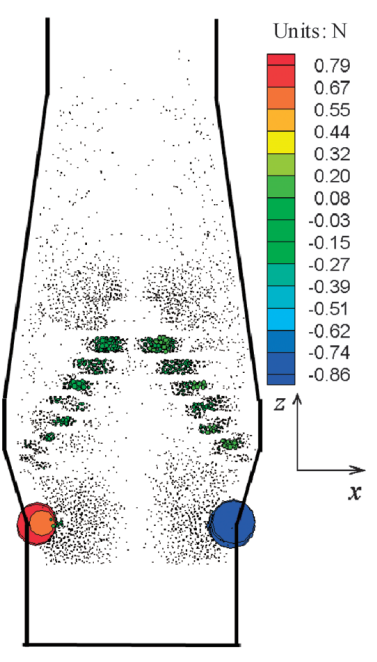

(b)
Fig. 7. Spatial distributions of the particle-fluid interaction forces: (a), in the vertical direction; and (b), in the horizontal direction.

standing of multiphase flow inside BF.

\subsection{Solid Flow in the Hearth}

To reduce the production cost, it is important to extend BF life, avoid BF hearth erosion and maintain the stable operation at a high productivity and low coke rate. Better understanding particle packing and flow, and their effect on liquid iron and slag flow in the hearth is helpful to achieve this goal. The packing structure in the hearth, e.g. the formation of coke free zone, affects the liquid drainage. ${ }^{34,35,44,45)}$ The flow of particles in the hearth is mainly driven by the downward gravitational and upward buoyancy forces, and hence strongly affected by the level of liquid and the position of discharging hole due to the upward buoyancy forces. ${ }^{34)}$ An attempt was recently made by Nouchi et al. ${ }^{35)}$ to simulate the solid flow in BF hearth and reveal the formation mechanisms of dead zone. However, their study was confined to the hearth region with an as- 

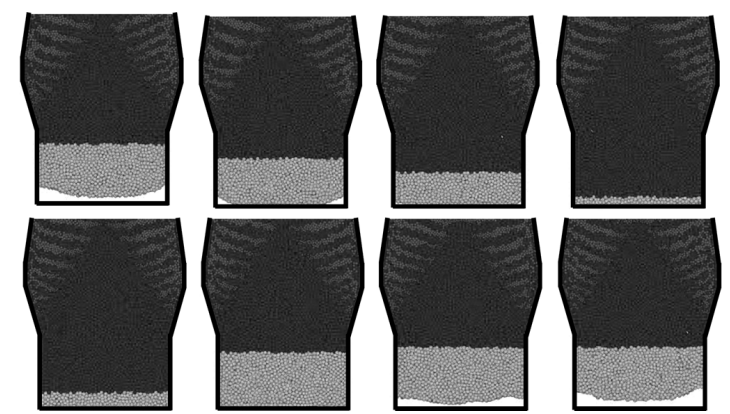

Fig. 8. Snapshots of solid flow patterns with liquid level decreasing (top) and increasing (bottom) in the hearth with time interval $2.4 \mathrm{~s}$.

sumed stress distribution acting on the (top) particles in the hearth. Also, the effect of gas phase was not considered. In the present work, the entire BF geometry is considered, and then the effects of some important parameters including liquid level, coke discharging rate, and gas flow rate on the hearth solid flow behavior are examined.

Figure 8 shows the snapshots of solid particles in the hearth with decreasing or increasing liquid level, which represents the tapping process or accumulating process of liquid iron in the hearth. It is observed that the coke-free space forms below the coke bed. Due to coke consumption in the raceway, the coke-free zone near the periphery of the hearth is larger than near the centre, where the maximum solids stress occurs, as indicated in Fig. 6(a). With liquid level decreasing, the solid particles in the central region then firstly touch the bottom when the liquid buoyancy force, particle-gas vertical drag force and wall friction forces cannot support the whole particle bed. Under the simulation conditions imposed, the coke-free zone decreases and finally disappears. Conversely, as liquid iron accumulates in the hearth and reaches a threshold level, the particle bed is lifted up and begins to float. The bottom profile of the coke-free zone is not a simple horizontal line.

The coke consumption rate in the raceway corresponds to the productivity of a BF. High consumption rate may affect the solid flow behavior in the hearth. Figure 9(a) shows the solid flow pattern in the hearth when there is no gas or solid flow. The particle bed is supported by the liquid buoyancy force, and the force from the bottom wall and friction forces from sidewalls. When solid flow rate applies, as shown in Fig. 9(b), a coke-free zone can form in the corner. This is caused by a decrease in solid stress near the sidewall region with increasing coke consumption rate.

Furthermore, the coke consumption also occurs in the hearth, which involves the chemical reactions, i.e. coke solution at the interface of liquid and solid. Such a reaction is affected by packing condition and residence time of metal and slag. To examine such an effect, coke particles are here discharged from different regions at the interface of liquid and solid at a rate of 1 particle per 100 time steps. Figure 10 shows the solid flow patterns and the corresponding velocity field for different coke discharging regions, which represents the coke solution. It can be observed that the profile of coke-free zone is significantly affected by discharging regions. When the region locates close to the wall, the profile is similar to that from the raceway. With the dis-

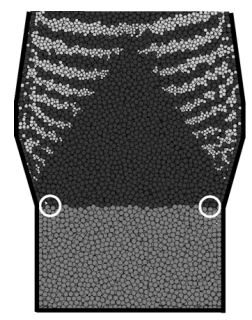

(a)

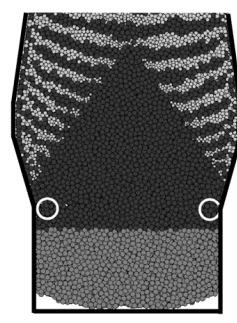

(b)

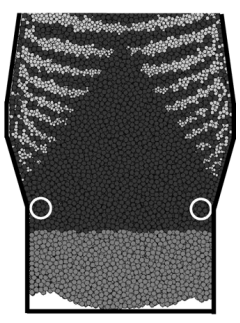

(c)
Fig. 9. Effect of particle discharging rate from the raceway on the solid flow pattern in the hearth: (a), $0 \mathrm{~kg} \cdot \mathrm{s}^{-1} ;$ (b), $7.34 \mathrm{~kg} \cdot \mathrm{s}^{-1}$; and (c), $14.7 \mathrm{~kg} \cdot \mathrm{s}^{-1}$.

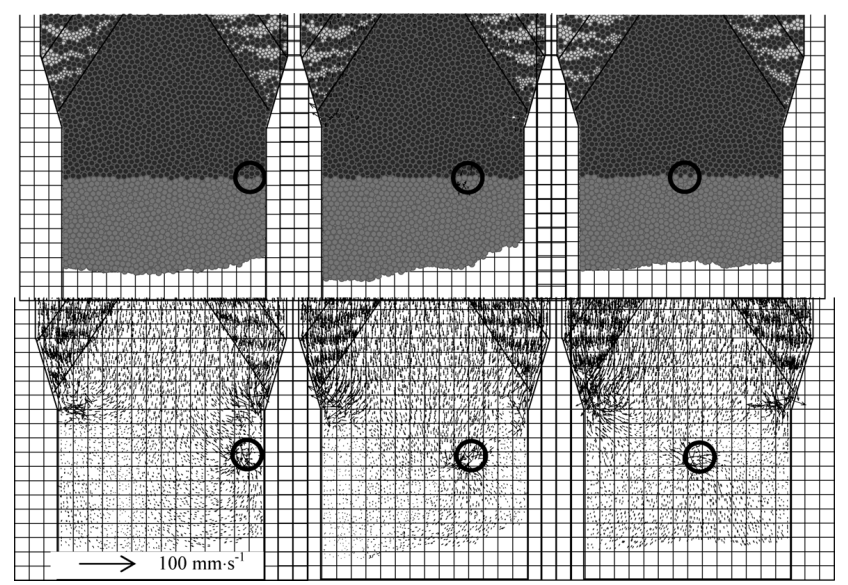

Fig. 10. Solid flow patterns (top) and corresponding solid velocity vectors (bottom) in the hearth for different discharging region of coke particles (left: close to the wall; middle: $1 / 4$ hearth diameter from the wall; right: $1 / 2$ hearth diameter from the wall).

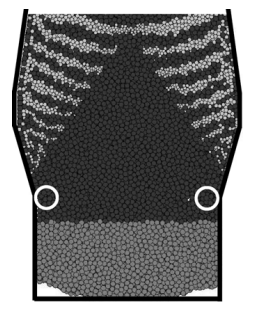

(a)

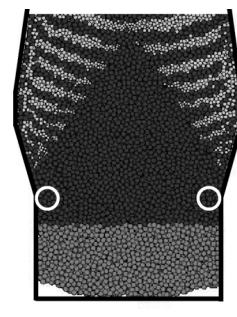

(b)

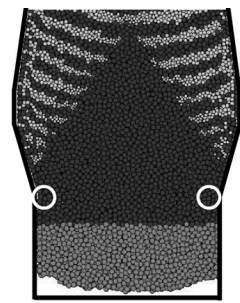

(c)
Fig. 11. Solid flow patterns at the bottom part for different gas velocities: (a), $0 \mathrm{~m} \cdot \mathrm{s}^{-1}$; (b), $30 \mathrm{~m} \cdot \mathrm{s}^{-1}$; (c), $45 \mathrm{~m} \cdot \mathrm{s}^{-1}$.

charging region moves to the centre, the profile changes significantly due to the decreased stress pressure around the discharging region. Then particles in the liquid hearth flow towards the discharging region under the strong buoyancy force from liquid. Thus, in a BF, the coke solution in the hearth may not be uniform, and it will result in complicated flow pattern of coke particles.

Gas blast into the furnace has an impact on the solid flow, particularly in the raceway region. The vertical particle-fluid interaction force could partially balance the weight of particle bed. With gas flow rate increasing, the pressure drop becomes higher, which can be reflected by the changes of solid flow in the hearth, as shown in Fig. 11. The coke free zone is larger with the increase of gas flow rate. The particle bed may leave the bottom wall and float 
in the liquid. Correspondingly, on one hand, the liquid level decreases, which affects the liquid drainage. On the other hand, such a float motion of coke bed enhances the renewal of deadman. As indicated in the physical experiment, ${ }^{41)}$ the particle movement induced by the sink-float motion of hearth coke bed is an indispensable mechanism in the evaluation of deadman renewal.

\section{Conclusions}

A DPS-CFD approach is developed to study the transient gas and particle flow in a model BF, in which complicated phenomena are considered. The model is featured by: (i) consideration of both coke and ore particles with layered structure; (ii) three types of shapes of cohesive zones (inverse V, V and W); (iii) shrinkage of ore particles in the cohesive zone; (iv) automatic detection of ore and coke layers, and transient gas-solid flow in the cohesive zone; (v) coke consumption in the raceway and hearth with hearth liquid included. It is shown that such an approach can capture the main flow features of transient distributions of ore and coke layers, and gas flow field. Ore layers in the cohesive zone determine the gas flow direction, which in turn affects the solid flow. The simulation has been extended to consider the liquid presence in the furnace hearth. A coke-free zone can form in the hearth, and its profile is affected by the amount of liquid accumulated in the hearth, coke consumption rate and gas flow rate. The present simulation study has shown that the complicated multiphase flow behaviour can be examined by DPS-CFD approach with an advantage that microscopic information such as particle velocities and forces can be analysed for developing a better understanding of the transient multiphase-flow in an ironmaking BF. The approach can be extended to consider thermo-chemical behaviour, hence offering a new way to elucidate the complicated phenomena in this traditionally regarded "black box" reactor. Work in this direction is now undertaken and hopefully the progress can be reported in the future.

\section{Aknowledgements}

The authors are grateful to BlueScope Steel and Australian Research Council (ARC) for the financial support of this work.

\section{Nomenclature}

$C_{\mathrm{d} 0}$ : Fluid drag coefficient on an isolated particle, dimensionless

$c_{n}$ : Normal damping coefficient, dimensionless

$c_{t}$ : Tangential damping coefficient, dimensionless

$d_{p}$ : Particle diameter of coke particles (m)

$d_{\text {ore }}$ : Transient diameter of ore particles in the cohesive zone (m)

$d_{0, \text { ore }}$ : Original diameter of ore particles before entering the cohesive zone $(\mathrm{m})$

$d_{c, \text { ore }}$ : Critical diameter of ore particles when leaving the cohesive zone $(\mathrm{m})$

$E$ : Young's modulus $(\mathrm{Pa})$

$\mathbf{f}_{c}$ : Particle-particle contact force $(\mathrm{N})$

$\mathbf{f}_{d}$ : Particle-particle damping force $(\mathrm{N})$

$\mathbf{f}_{p f, i}:$ Particle-fluid interaction force on particle $i(\mathrm{~N})$

$\mathbf{F}_{p f}$ : Volumetric particle-fluid interaction force in a computational cell $\left(\mathrm{N} \cdot \mathrm{m}^{-3}\right)$

g: Gravitational acceleration $\left(\mathrm{m} \cdot \mathrm{s}^{-2}\right)$

I : Moment of inertia of particle $\left(\mathrm{kg} \cdot \mathrm{m}^{2}\right)$

$k_{c}$ : Number of particles in contact with particle $i$, dimensionless

$\mathbf{M}_{r}$ : Rolling torque $(\mathrm{N} \cdot \mathrm{m})$

$\mathbf{M}_{t}$ : Tangential torque $(\mathrm{N} \cdot \mathrm{m})$

$m$ : Mass of particle $(\mathrm{kg})$

$N$ : Number of particles, dimensionless

$p$ : Fluid pressure $(\mathrm{Pa})$

$\mathbf{R}$ : Vector from the mass centre of the particle to the contact point $(\mathrm{m})$

Re: Reynolds number, dimensionless

$t$ : Time (s)

$\Delta t:$ Time step (s)

u : Fluid velocity $\left(\mathrm{m} \cdot \mathrm{s}^{-1}\right)$

$U_{f}$ : Gas superficial velocity at the furnace throat $\left(\mathrm{m} \cdot \mathrm{s}^{-1}\right)$

v: Particle translational velocity $\left(\mathrm{m} \cdot \mathrm{s}^{-1}\right)$

$\mathbf{V}_{n, i j}$ : Normal relative velocity between particles $i$ and $j$ $\left(\mathrm{m} \cdot \mathrm{s}^{-1}\right)$

$\mathbf{V}_{t, i j}$ : Tangential relative velocity between particles $i$ and $j\left(\mathrm{~m} \cdot \mathrm{s}^{-1}\right)$

$\Delta V: \quad$ Volume of a computational cell $\left(\mathrm{m}^{3}\right)$

$Z_{\text {top }}:$ The vertical distance defined in Fig. $1(\mathrm{~m})$

$Z_{\text {bot }}$ : The vertical distance defined in Fig. 1 (m)

$Z_{p}$ : The vertical distance of ore particles defined in Fig. 1 (m)

Greek

$\chi$ : Empirical coefficient defined in Table 1, dimensionless

$\delta_{t, \text { max }}: \quad$ Maximum $\delta_{t}$ when sliding starts (m)

$\boldsymbol{\delta}_{n}$ : Relative normal displacement at contact (m)

$\delta_{t}$ : Relative tangential displacement at contact (m)

$\hat{\boldsymbol{\delta}}_{\boldsymbol{t}}$ : Unit vector of $\boldsymbol{\delta}_{\boldsymbol{t}}$ dimensionless

$\varepsilon$ : Porosity, dimensionless

$\mu_{f}$ : Fluid molecular viscosity $\left(\mathrm{kg} \cdot \mathrm{m}^{-1} \cdot \mathrm{s}^{-1}\right)$

$\mu_{r}$ : Rolling friction coefficient (m)

$\mu_{s}$ : Sliding friction coefficient, dimensionless

$v$ : Poisson ratio, dimensionless

$\rho:$ Density $\left(\mathrm{kg} \cdot \mathrm{m}^{-3}\right)$

$\tau$ : Stress tensor $(\mathrm{Pa})$

$\omega:$ Angular velocity $\left(\mathrm{s}^{-1}\right)$

$\hat{\omega}$ : Unit vector of $\omega$, dimensionless

Subscripts

$c:$ Contact

$d$ : Damping

$f$ : Fluid

$i$ : $\quad$ Particle $i$

$i j$ : $\quad$ Between particles $i$ and $j$

$j:$ Particle $j$

$l$ : Liquid

$n$ : Normal component

$p$ : Particle

$r$ : Rolling

$t$ : Tangential component

$w$ : Wall 


\section{REFERENCES}

1) L. Z. Khodak and Y. I. Borosov: Powder Technol., 4 (1970/1971), 187.

2) M. Shimizu, A. Yamaguchi, S. Inaba and Y. Matsui: Trans. Iron Steel Inst. Jpn., 26 (1986), 189.

3) C. K. Ho, Y. M. Chen, C. I. Lin and J. R. Jeng: Powder Technol., 63 (1990), 13.

4) H. Takahashi and N. Komatsu: ISIJ Int., 33 (1993), 655.

5) B. D. Wright: $\mathrm{PhD}$ Thesis, The University of New South Wales, (2001).

6) H. Takahashi, H. Kawai, M. Kobayashi and T. Fuku: ISIJ Int., 45 (2005), 1386.

7) J. I. Yagi: ISIJ Int., 33 (1993), 619.

8) X. F. Dong, A. B. Yu, J. I. Yagi and P. Zulli: ISIJ Int., 47 (2007), 1553.

9) J. Z. Chen, T. Akiyama, J. I. Yagi and H. Takahashi: ISIJ Int., 33 (1993), 664.

10) S.J. Zhang, A. B. Yu, P. Zulli, B. Wright and U. Tüzün: ISIJ Int., 38 (1998), 1311

11) J. A. Castro, H. Nogami and J. I. Yagi: ISIJ Int., 42 (2002), 44.

12) S. A. Zaimi, T. Akiyama, J. B. Guillot and J. I. Yagi: ISIJ Int., 40 (2000), 332.

13) H. Nogami and J. I. Yagi: ISIJ Int., 44 (2004), 1826.

14) Z. Y. Zhou, A. B. Yu and P. Zulli: Prog. Comput. Fluid Dyn., 4 (2004), 39 .

15) P. A. Cundall and O. D. L. Strack: Geotechnique, 29 (1979), 47.

16) H. P. Zhu, Z. Y. Zhou, R. Y. Yang and A. B. Yu: Chem. Eng. Sci., 62 (2007), 3378

17) H. P. Zhu, Z. Y. Zhou, R. Y. Yang and A. B. Yu: Chem. Eng. Sci., 63 (2008), 5728.

18) D. Pinson, B. Wright and A. B. Yu: 8th Int. Conf. on Bulk Materials Storage, Handling and Transportation, ed. by P. Wypych, The Instiution of Engineers, Wollongong, Australia, (2004), 294.

19) Y. Kajiwara, T. Inada and T. Tanaka: Trans. Iron Steel Inst. Jpn., 28 (1988), 916.

20) H. Mio, M. Akashi, A. Shimosaka, Y. Shirakawa, J. Hidaka and S. Matsuzaki: Chem. Eng. Sci., 64 (2009), 1019.

21) H. Mio, S. Komatsuki, M. Akashi, A. Shimosaka, Y. Shirakawa, J. Hidaka, M. Kadowaki, S. Matsuzaki and K. Kunitomo: ISIJ Int., 48
(2008), 1696.

22) H. Kawai and H. Takahashi: ISIJ Int., 44 (2004), 1140.

$23)$ Z. Y. Zhou, H. P. Zhu, A. B. Yu, B. Wright, D. Pinson and P. Zulli: ISIJ Int., 45 (2005), 1828.

24) Z. Y. Zhou, H. P. Zhu, A. B. Yu, B. Wright and P. Zulli: Comput. Chem. Eng., 32 (2008), 1760.

25) T. Nouchi, T. Sato, M. Sato, K. Takeda and T. Ariyama: ISIJ Int., 45 (2005), 1426.

26) H. Mio, K. Yamamoto, A. Shimosaka, Y. Shirakawa and J. Hidaka: ISIJ Int., 47 (2007), 1745.

27) B. H. Xu, A. B. Yu, S. J. Chew and P. Zulli: Powder Technol., 109 (2000), 13.

$28)$ B. H. Xu, Y. Q. Feng, A. B. Yu, S. J. Chew and P. Zulli: Powder Handl. Process., 13 (2001), 71.

29) Y. Q. Feng, D. Pinson, A. B. Yu, S. J. Chew and P. Zulli: Steel Res. Int., 74 (2003), 523.

30) H. Nogami, H. Yamaoka and K. Takanani: ISIJ Int., 44 (2004), 2150

31) S. Yuu, T. Umekage and T. Miyahara: ISIJ Int., 45 (2005), 1406.

32) T. Umekage, S. Yuu and M. Kadowaki: ISIJ Int., 45 (2005), 1416.

33) V. Singh, G. S. Gupta and S. Sarkar: Chem. Eng. Sci., 62 (2007), 6102.

34) T. Nouchi, K. Takeda and A. B. Yu: ISIJ Int., 43 (2003), 187.

35) T. Nouchi, A. B. Yu and K. Takeda: Powder Technol., 134 (2003), 98.

36) H. P. Zhu, Z. Y. Zhou, A. B. Yu and P. Zulli: Granul. Matter, 11 (2009), 269.

37) Y. C. Zhou, B. D. Wright, R. Y. Yang, B. H. Xu and A. B. Yu: Physica A, 269 (1999), 536.

38) Y. Q. Feng and A. B. Yu: Ind. Eng. Chem. Res., 43 (2004), 8378.

39) Z. Y. Zhou, A. B. Yu and P. Zulli: AIChE J., 55 (2009), 868.

$40)$ B. Y. Guo, P. Zulli and A. B. Yu: 5th Int. Conf. on CFD in the Process Industries, CSIRO, Melbourne, Australia, (2006).

41) H. Nogami, K. Toda, S. Pintowantoro and J. I. Yagi: ISIJ Int., 44 (2004), 2127.

42) H. Takahashi and H. Kawai: Tetsu-to-Hagané, 87 (2001), 373.

43) X. F. Dong, D. Pinson, S. J. Zhang, A. B. Yu and P. Zulli: Appl. Math. Model., 30 (2006), 1293.

44) K. Nishoka, T. Maeda and M. Shimizu: ISIJ Int., 45 (2005), 1496.

45) T. Nouchi, M. Yasui and K. Takeda: ISIJ Int., 43 (2003), 175. 